\title{
Risky Behaviors of People Living with AIDS: Experiences from an Income-Generation Skills Training Centre in Lusaka
}

\author{
Hector Chiboola*1 and Choolwe Chiboola ${ }^{2}$ \\ ${ }^{1}$ ChresoUniversity, Faculty of Social Sciences, Zambia \\ ${ }^{2}$ Kabwe University, Faculty of Counselling Studies, Zambia
}

Submission: April 10, 2018; Published: June 08, 2018

*Corresponding author: Hector Chiboola, researcher and associate director of postgraduate studies, Chreso university, Email: hectorchiboola@yahoo.com

\begin{abstract}
The study aimed to find out whether or not HIV testing and counseling helps to prevent indulgence in risky behaviors amongst people living with AIDS. It used a qualitative research methodology and deployed a holistic single-case study design. The sample consisted of 20 adult participants in the age range 20-40 years, all of them people living with AIDS. The sample was drawn from an income-generation skills training centre; and it was selected based on the purposive sampling method. Data collection was elicited through structured individual interview. The data was analyzed at various levels which included thematic analysis, content analysis, comparative analysis and interpretive analysis. This study showed that even when people are tested and counseled for HIV infection they neither live positively nor avoid indulging in risky behaviors despite knowing their HIV status. These findings have serious implications for policy and programming of interventions for HIV prevention at community level. There is need for targeted effort to reach out to people living with AIDS through ongoing supportive psychosocial counseling and antiretroviral treatment. The findings of this study are likely to inform policy planners, counseling psychologists, psychosocial counselors and educationists.
\end{abstract}

Keywords: Testing and counseling; People with AIDS; Risky behaviors; HIV testing; Syndrome; Culture; Race; Occupation; Education; Gender; Age; Psychologists; Income; Epidemiology; Antiretroviral treatment

\section{Introduction}

This article presents qualitative research on the case study risky behaviors of people living with AIDS (PLWA) at an incomegeneration skills training centre in Lusaka, Zambia. The study aimed to find out whether or not HIV tests and counseling helps to prevent indulgence in risky behaviors amongst people living with AIDS. The human immunodeficiency virus/ acquired immune deficiency syndrome (HIV/AIDS) pandemic is increasingly becoming more heterogeneous and is constantly changing: it knows no regional or continental borders; it transcends race, culture, occupation, education, gender and age; and it is multifaceted [1]. The identification of socio behavioral and environmental factors for HIV transmission is important for the control of further infections, because they may offer additional opportunities for intervention. It is equally important to understand the sexual preferences and practices of specific population groups at community level since the effective control of HIV transmission largely depends on people's beliefs and vulnerability, their attitudes and perceptions, and what they do to protect themselves and others from acquiring HIV infection [2].
Presently, Zambia still remains amongst the countries most seriously affected by the HIV epidemic in sub-Saharan Africa. Whereas several other diseases are currently more prevalent in the general population, there are some important characteristics of HIV and its epidemiology that cause the AIDS disease to have a greater socioeconomic impact in sub-Saharan Africa. A great number of HIV prevalence studies have been carried out at different stages of the epidemic providing valuable and reliable data. For instance in Zambia, according to the Central Statistical Office and others [3], in 2007 the national HIV prevalence among the adult population aged 15-49 years was $14 \%$, representing women at $16 \%$ and men at $12 \%$. In the same year, the geographical variation in HIV prevalence among the adult population aged 15-49 years was higher in urban communities (20\%) than in rural communities (10\%), representing women in urban $(23 \%)$ and in rural $(11 \%)$. These data show that women are bearing the bigger chunk of HIV infection at national level in addition to their responsibilities of providing care, support and management needs to other family members at household level. The HIV epidemic is likely to continue being a major public health 
and social problem in Zambia for several decades to come, with severe socioeconomic and psychological impact across various population groups at community level [4].

As more HIV-infections are reported, the cost in terms of human suffering and loss of life increases. The overall threat to human development is manifest in many African countries as the sexually, socially and economically productive population slowly fades away. AIDS is perhaps one of the diseases presenting with the highest statistics in the world and presently costing huge sums of money in research and programmatic interventions. Zambia has adopted a multisectoral approach in response to the HIV/ AIDS pandemic, and a wide range of vertical programmers and interventions have been implemented to mitigate the situation since the emergence of HIV epidemic slightly over a generation ago. Amongst the notable programmes or interventions are: HIV testing and counseling; partner notification; information, education and sensitization campaigns; prevention of motherto-child transmission of HIV; communication for behavior change; condom promotion and usage; voluntary medical male circumcision; antiretroviral treatment; treatment of opportunistic infections; laboratory diagnostic procedures; safe blood transfusions; community/home based care; healthful living and supportive care; and research. The impact of most of these interventions is visible as evidenced, for instance in Zambia, through reduction of the national HIV prevalence from $16 \%$ in 2002 to $14 \%$ in 2007 , although the reduction is not statistically significant if interpreted against the impact over a period of five years [3]. Universal HIV testing and counseling is being promoted to increase care and linkages for wider coverage and social impact to people living with or affected by the AIDS virus [5].

What has remained a gap is the seemingly lack of information about whether or not people avoid indulging in risky behaviors after knowing their HIV status. The rarity or unavailability of information on indulgence in risky behaviors motivated this study because it was unique and typical [6]; and it was likely to yield fundamental insight into a rare but important process that offered no obvious point of comparison [7]. Therefore, the primary research question for this study was: Does HIV testing and counseling help to prevent indulgence in risky behaviors amongst people living with AIDS?

In the context of this study, the term 'HIV testing' refers to the use of testing protocols intended to detect the presence of antibodies in the human blood that signifies exposure or nonexposure to HIV infection; and the term 'HIV counseling' refers to a process of dialogue and interaction aimed at facilitating understanding of the physical and psychosocial issues about HIV/AIDS, usually segmented in pre-test counseling undertaken prior to the test and post-test counseling undertaken after the test. The term 'indulgence' implies willingly taking one's pleasure or freely yielding to desires in order to gratify personal wishes; and the term 'risky behavior' implies exposure to behaviors or actions that may cause infection, injury, harm or bad consequences. The term 'prevent' refers to actions taken to hinder, avoid or stop something happening or progressing.

\section{Methods}

The study used a qualitative research methodology and deployed a holistic single-case study design. The choice for this study design was motivated by a richness and depth of information it offers in comparison to other research designs [8]. The method of choice was purposive sample; and this was deemed the only suitable methodological approach to achieve the desired sample for the study [9]. The sample consisted of 20 adult participants, all of them people living with AIDS, drawn from an income-generation skills training centre. Of the 20 participants, 10 were male and 10 were female; 4 were married, 5 separated, 4 divorced, 4 widowed, and 3 single; 7 had attained primary level, 12junior secondary level, and 1 college level education; and 7 were aged 20-29 years, 11 were 30-39 years, and 2 above 40 years. The selection of participants was based on the assumption that the most can be learned from them as people living with AIDS.

The interview schedule was developed by the researchers to collate information from participants; it was pre-tested on a small sample; it was approved by the appropriate research ethics committee prior to use in the field; and it was intended to assure objectivity, reliability, uniformity and authenticity of the information collected. The interview schedule contained twelve question items, of which only four key research questions linked to indulgence in risky behaviors are presented herein. The first question inquired on the gender of participants; the second on their marital status; the third on their educational level; and the fourth on their HIV testing and counseling. It was the researchers' view that these questions would yield fundamental insight and illuminate the case study in the context of selected risky behaviors, namely, sexual partner, pregnancy, condom use, beer drinking, cigarette smoking, and suffering from sexually transmitted diseases (STD).

Each participant filled out the interview schedule individually and on the same day and time in the presence of researchers; and this was intended to assure transparency, validity and authenticity of the data collected [10]. Written informed consent was obtained from all the participants prior to the individual interview. The identity of participants was anonymous; and the study was conducted based on fundamental ethical principles of autonomy, beneficence, non-maleficence, justice, and protection from disclosure [11]. Data collection was concurrent with data analysis; and the data were analyzed at various levels which included thematic analysis, content analysis, comparative analysis and interpretive analysis. This approach was deemed to have met the criteria of sufficiency for qualitative data analysis that place emphasis on the need for completeness, robustness and sensibleness. 


\section{Global Journal of Archaeology \& Anthropology}

\section{Results}

The research findings presented in this article are restricted to:

i. The understanding of key risky behaviors;

ii. The influence of social factors on personal choices and preferences to indulge in risky behaviors; and

iii. The effect of HIV testing and counseling in relation to sexual behavior change. The focus is on illuminating and generating insight about the case study.

\section{Risky behaviors}

As reflected in Table 1, the selected key risky behaviors were: having a sexual partner, making someone or becoming pregnant, not using condoms during sexual intercourse, drinking beer, and smoking cigarettes. It is manifest from Table 1 that 6 of the females and 5 of the males reported to having or maintaining a sexual partner at the time of interview. Of these, only 2 of the males reported using condoms with their sexual partners; while the remainder (9) did not. Two inferences can be drawn from these findings: first, these data show that a remarkable number of PLWA indulged in penetrative sex without using condoms; and second, many PLWA indulged in casual sex considering that only 4 of the total participants reported having been married at the time of interview. Table 1 also shows that of the 11 participants with sexual partners, 6 of the females reported to have gotten pregnant and 2 of the males impregnated someone during the period of their HIV-infection. It can be inferred from these data that a majority of PLWA (8/11) willingly risked a pregnancy despite knowing their HIV status. It is apparent that pregnancy when the woman is HIV-infected poses challenges of infecting the unborn child, especially in the absence of HIV prevention of mother-to-child transmission intervention.

Further Table 1 shows that of the 20 participants, 5 of the males and 2 of the females reported that they drank beer, while the remainder (13) did not; and 3 of the males and 1 of the females reported that they smoked cigarettes, while the remainder (16) did not. These data show that more men than women either drank beer or smoked cigarettes respectively, despite knowing their HIV status and the health risk factors associated with such social behaviors and practices.

Table 1: Risky behaviors

\begin{tabular}{|c|c|c|c|c|c|}
\hline & & & & & Total \\
\hline & Ris & & Male & Female & \\
\hline \multirow{2}{*}{1} & \multirow{2}{*}{ Sexual partner } & Yes & 5 & 6 & 11 \\
\hline & & No & 5 & 4 & 9 \\
\hline \multirow{2}{*}{2} & \multirow{2}{*}{ Pregnancy } & Yes & 2 & 6 & 8 \\
\hline & & No & 8 & 4 & 12 \\
\hline \multirow{2}{*}{3} & \multirow{2}{*}{ Condom use } & Yes & 2 & 0 & 2 \\
\hline & & No & 8 & 10 & 18 \\
\hline \multirow{2}{*}{4} & \multirow{2}{*}{ Beer drinking } & Yes & 5 & 2 & 7 \\
\hline & & No & 5 & 8 & 13 \\
\hline \multirow{2}{*}{5} & \multirow{2}{*}{ Cigarette smoking } & Yes & 3 & 1 & 4 \\
\hline & & No & 7 & 9 & 16 \\
\hline
\end{tabular}

\section{Social factors}

As reflected in Table 2, only the widowed participants never indulged in any of the five key risky behaviors, while the others did variously irrespective of their marital status. Table
2 also shows that almost all participants (9/11) who reported having had a sexual partner never used condoms during sexual intercourse irrespective of their marital status; and only 2 participants reported condom use.

Table 2: Marital status.

\begin{tabular}{|c|c|c|c|c|c|c|c|c|}
\hline & & & \multicolumn{5}{|c|}{ Marital status } & \multirow{3}{*}{\begin{tabular}{|r|} 
Tota \\
11 \\
\end{tabular}} \\
\hline & \multicolumn{2}{|c|}{ Risky behavior } & Married & Single & Separated & Divorced & Widowed & \\
\hline \multirow{2}{*}{1} & \multirow{2}{*}{ Sexual partner } & Yes & 4 & 2 & 4 & 0 & 1 & \\
\hline & & No & 0 & 3 & 0 & 4 & 2 & 9 \\
\hline \multirow{2}{*}{2} & \multirow{2}{*}{ Pregnancy } & Yes & 2 & 1 & 4 & 0 & 1 & 8 \\
\hline & & No & 2 & 4 & 0 & 4 & 2 & 12 \\
\hline \multirow{2}{*}{3} & \multirow{2}{*}{ Condom use } & Yes & 1 & 1 & 0 & 0 & 0 & 2 \\
\hline & & No & 3 & 4 & 4 & 4 & 3 & 18 \\
\hline
\end{tabular}




\begin{tabular}{|c|c|c|c|c|c|c|c|c|c|}
\hline \multirow{2}{*}{4} & \multirow{2}{*}{ Beer drinking } & Yes & 2 & 2 & 2 & 0 & 1 & 7 \\
\cline { 3 - 9 } & & No & 2 & 3 & 2 & 4 & 2 & 13 \\
\hline \multirow{2}{*}{5} & \multirow{2}{*}{ Cigarette smoking } & Yes & 0 & 3 & 1 & 0 & 0 & 4 \\
\cline { 3 - 10 } & & No & 4 & 2 & 3 & 4 & 3 & 16 \\
\hline
\end{tabular}

Furthermore, Table 3 shows that almost all participants (9/11) who reported having had a sexual partner never used condoms during sexual intercourse irrespective of their educational level; and only 2 participants reported condom use. Table 3 also shows that of the other risky behaviors, participants educated up to junior secondary level indulged the most in having sexual partners (7), facilitating pregnancies (5), beer drinking (4) and cigarette smoking (4) than the other two categories. It is manifest from these data that neither marital status nor level of education remarkably influenced PLWA to live positively and avoid indulging in risky behaviors.

Table 3: Educational level.

\begin{tabular}{|c|c|c|c|c|c|c|}
\hline & & & \multicolumn{3}{|c|}{ Educational level } & \multirow{3}{*}{\begin{tabular}{|c|} 
Total \\
11 \\
\end{tabular}} \\
\hline & \multicolumn{2}{|c|}{ Risky behavior } & Primary & Secondary & College & \\
\hline \multirow{2}{*}{1} & \multirow{2}{*}{ Sexual partner } & Yes & 3 & 7 & 1 & \\
\hline & & No & 4 & 5 & 0 & 9 \\
\hline \multirow{2}{*}{2} & \multirow{2}{*}{ Pregnancy } & Yes & 3 & 5 & 0 & 8 \\
\hline & & No & 4 & 7 & 1 & 12 \\
\hline \multirow{2}{*}{3} & \multirow{2}{*}{ Condom use } & Yes & 0 & 1 & 1 & 2 \\
\hline & & No & 7 & 11 & 0 & 18 \\
\hline \multirow{2}{*}{4} & \multirow{2}{*}{ Beer drinking } & Yes & 2 & 4 & 1 & 7 \\
\hline & & No & 5 & 8 & 0 & 13 \\
\hline \multirow{2}{*}{5} & \multirow{2}{*}{ Cigarette smoking } & Yes & 0 & 4 & 0 & 4 \\
\hline & & No & 7 & 8 & 1 & 16 \\
\hline
\end{tabular}

\section{Testing and counseling}

As reflected in Table 4, there was a marginal difference between the participants that were pre-counseled and tested who maintained a sexual partner (5) and those that were tested but not pre-counseled (6). Further, there was no difference between the female participants who reported having a sexual partner that got pregnant despite having been pre-counseled and tested (3) and those that were tested but not pre-counseled (3). The results are the same for beer drinking and cigarette smoking. These findings clearly show that pre-counseling and knowing one's HIV status did not positively influence sexual behavior preferences for PLWA given that almost all the participants (10/11) that maintained a sexual partner reported having suffered from sexually transmitted diseases since their previous HIV test. Based on these data, it is plausible to conclude that knowing one's HIV status and being pre-test counseled neither leads to avoidance of nor prevents indulgence in risky behaviors (Table 4).

Table 4: Testing and counseling

\begin{tabular}{|c|c|c|c|c|c|c|c|}
\hline & & & \multicolumn{4}{|c|}{ Precounselled Tested But Not and Tested Precounselled } & \multirow[t]{2}{*}{ Total } \\
\hline & \multicolumn{2}{|c|}{ Risky behavior } & Male & Female & Male & Female & \\
\hline \multirow{2}{*}{1} & \multirow{2}{*}{ Sexual partner } & Yes & 2 & 3 & 3 & 3 & 11 \\
\hline & & No & 3 & 4 & 2 & 0 & 9 \\
\hline \multirow{2}{*}{2} & \multirow{2}{*}{ Pregnancy } & Yes & 0 & 3 & 2 & 3 & 8 \\
\hline & & No & 5 & 4 & 3 & 0 & 12 \\
\hline \multirow{2}{*}{3} & \multirow{2}{*}{ Condom use } & Yes & 2 & 0 & 0 & 0 & 2 \\
\hline & & No & 3 & 7 & 5 & 3 & 18 \\
\hline \multirow{2}{*}{4} & \multirow{2}{*}{ Beer drinking } & Yes & 2 & 1 & 3 & 1 & 7 \\
\hline & & No & 3 & 6 & 2 & 2 & 13 \\
\hline
\end{tabular}




\begin{tabular}{|c|c|c|c|c|c|c|c|}
\hline \multirow{2}{*}{5} & \multirow{3}{*}{ Cigarette smoking } & Yes & 1 & 1 & 2 & 0 & 4 \\
\cline { 3 - 8 } & & No & 4 & 6 & 3 & 3 & 16 \\
\hline \multirow{2}{*}{6} & \multirow{2}{*}{ Suffered from STD } & Yes & 3 & 3 & 3 & 1 & 10 \\
\cline { 3 - 8 } & & No & 2 & 4 & 2 & 2 \\
\hline
\end{tabular}

\section{Discussion}

The study shows that a large proportion of the participants indulged in risky behaviors, that is, they had sexual partners, got pregnant or impregnated someone, never used condoms, drank beer, smoked cigarettes, and suffered from STD. Exposure to casual sex has close links with getting infected with HIV and STD; and excessive cigarette smoking can cause lung diseases, classical opportunistic infections common in people living with AIDS [12]. Failure to negotiate for condom use partly signifies a lack of knowledge and practical skills on how to use condoms as well as a lack of emotional consideration for the health and sexual rights of other people. Sometimes it is influenced by the need for survival or economic gain. From a psychological perspective, the apparent denial and negative attitudes towards condoms is indicative of self-blame and self-stigmatization common amongst PLWA. Additionally, non-use of condoms and getting pregnant despite knowing one's HIV status is indicative of the power imbalance and women's inability to stand the pressures of male dominance and socio cultural influences from an African context. In contemporary African cultures and societies, women are expected to be submissive and perform sexual functions without question. It is in the context of this understanding that socio cultural practices of polygamy, extramarital sexual relationships, casual sex or supplemental sexual activities, and sexual ritual cleansing are perpetuated without recourse to HIV infection.

The indulgence of a majority of PLWA in risky behaviors could be due to psychological stress and desperation associated with feelings of anxiety, despondence, hopelessness and helplessness $[13,14]$. Others indulge in risky behaviors because of negligence and denial - insidiously wishing to infect another person as a form of revenge or expression of displaced anger for their changed situation. The underlying common assumption that alcohol makes one forget about stressful conditions or situations is just but a misconception. Excessive consumption of alcohol lowers a person's ability to think properly which may impair negotiation for safer sex, the proper and consistent use of condoms, and adherence to antiretroviral therapy and treatment of other opportunistic infections. Inadvertently, it is manifest that personal preferences and choices with regard to social behavior supersede the objects of HIV testing and counseling. This is a psychosocial dilemma with far reaching implications for the prevention and control of HIV transmission, particularly in the midst of poverty, gender based violence and inequality characteristic of the general population not only in Zambia, but in most other African countries as well. Ongoing supportive psychosocial counseling can be instrumental in facilitating sustainable behavioral and attitudinal change, as well as inducing desirable positive beliefs and perceptions about HIV infection and prevention.

\section{Conclusion}

The study has shown that even when people are tested and counseled for HIV infection they neither live positively nor avoid indulging in risky behaviors despite knowing their HIV status. HIV testing and counseling as a singular intervention has limitations with regard to influencing avoidance of risky behaviors amongst PLWA. This has implications for policy development and implementation: the prevention and control of HIV infection is multifaceted, and it is likely to remain problematic in different population groups for several decades to come. Therefore, there is need for targeted effort to reach out to people living with AIDS through ongoing supportive psychosocial counseling to facilitate sustainable socio behavioral change and antiretroviral therapy to improve healthful living and elongation of life for individuals, couples and families. It is worthy conducting another study involving a larger sample and geographical location so as to extend and consolidate the findings of the current study. Due to a small sample size, the results of this study are not conclusive and should be interpreted within the sphere of limitations and applications of qualitative case study research. Notwithstanding the foregoing, the findings of this study are likely to inform policy planners, counseling psychologists, psychosocial counselors and educationists.

\section{Acknowledgement}

The research project was implemented under the auspices of Chreso University and it was partially funded by the Zambia Counseling Council under a non-contract administrative arrangement, both of which are profoundly thanked. Equally, the authors would like to thank participants for their valuable information that formed the substance of this article.

\section{Disclaimer}

This article has not been published nor submitted for publication to any journal previously. It represents original work of the authors.

\section{Disclosure}

The authors have no conflict of interest or financial disclosure to make.

\section{References}

1. UNAIDS/WHO (2002) AIDS epidemic update. Geneva, Switzerland, Europe. 
2. Chiboola H (2006) HIV/AIDS counselling: A handbook. $\left(2^{\text {nd }} e d n\right)$, Lioness \& Dove, Lusaka, Zambia.

3. CSO (2009) Zambia demographic and health survey. Maryland: CSO \& Macro International Inc, Calverton, USA.

4. Barnett T, Whiteside A (2000) Guidelines for studies of the social and economic impact of HIV/AIDS. Best practice collection. UNAIDS, Geneva, Switzerland.

5. WHO (2012) Service delivery approaches to HIV testing and counseling (HTC): A strategic HTC programme framework. Geneva, Switzerland, Europe.

6. Yin RK (2009) Case study research: Design and methods. ( $4^{\text {th }}$ edn), Sage, London, UK.

7. Perecman E, Sara R, Curran SR (2006) A Handbook for Social Science Field Research: Essays \& Bibliographic Sources on Research Design and Methods. Thousand Oaks, Sage, California, USA.

This work is licensed under Creative Commons Attribution 4.0 License DOI: 10.19080/GJAA.2018.04.555640
8. Hanson EW, Creswell JW, Clark VLP, Petska KS, Creswell JD (2005) Mixed methods research design in counseling psychology. Journal of Counseling Psychology 52(2): 224-235.

9. Giddens A (2009) Sociology. ( $6^{\text {th }}$ edn), Polity, Cambridge, UK

10. McLeod J (2013) An introduction to research in counseling and psychotherapy. Sage, London, UK.

11. Beauchamp TL, Childress JF (1994) Principles of biomedical ethics. ( $4^{\text {th }}$ edn), NY: OUP, New York, USA.

12. Schneiderman N, Antoni MH, Saab PG, Ironson G (2001) Health psychology: Psychosocial and behavioral aspects of chronic disease management. Annual Reviews Psychology 52: 555-580.

13. Alloy LB, Riskind JH, Manos MJ (2005) Abnormal psychology: Current perspectives. ( ${ }^{\text {th }}$ edn), McGraw-Hill, New York, USA.

14. Hewstone M, Fincham DF, Foster J (2005) Psychology, (1 $1^{\text {st }}$ edn), Blackwell, Oxford, UK

\section{Your next submission with Juniper Publishers} will reach you the below assets

- Quality Editorial service

- Swift Peer Review

- Reprints availability

- E-prints Service

- Manuscript Podcast for convenient understanding

- Global attainment for your research

- Manuscript accessibility in different formats

( Pdf, E-pub, Full Text, Audio)

- Unceasing customer service

Track the below URL for one-step submission https://juniperpublishers.com/online-submission.php 